\title{
ANTHROPOMETRY, PHYSICAL ABILITY AND DISPENSARY OBSERVATION OF SCHOOL-AGE CHILDREN - CONTRIBUTION TO HEALTH PREVENTION AND PUBLIC HEALTH
}

\author{
Daniel Monov', Genoveva Ragyovska², Yulia Vitlyanova ${ }^{3}$ \\ ${ }^{1}$ Training and Research Sector of Public Health Inspector, Medical College, \\ Medical University of Varna \\ ${ }^{2}$ Department of Health Care, Faculty of Public Health, Medical University of Varna \\ ${ }^{3}$ Regional Health Inspectorate, Varna
}

\begin{abstract}
INTRODUCTION: Morphological /anthropometric/ indicators are the basis for assessing the physical growth of children of school age, the relevant organs and the whole body. External factors affect growth and development, especially during puberty. We set ourselves the task to analyze anthropometric studies of students in organized groups in Varna - on height, body weight, activity, and their dispensary observation by ICD for a period of two years - $2012-2014$.

MATERIALS AND METHODS: We have used reports, analyses, tests, data from prophylactic examinations and dispensary, anthropometric measurements, laboratory tests of RHI Varna, examination of physical abilities and more. Our methods included documentary, statistical, laboratory tests, physical abilities and more.

RESULTS: We explored the physical development of 80771 students in organized groups in Varna - 33669 for the 2012-2013 school year and 42918 for 2013-2014, divided into three groups: first group - norm, second group - extended norm and third group - outside the norm. We analyzed the physical abilities to pass and not pass the tests for norm and out of norm and the ones free from physical education and remedial gymnastics.

CONCLUSIONS: The share of anthropometric measurement of height and weight within the norm is highest in schoolchildren in group I (norm) - $\mathbf{8 7 . 0 \%}$ for a height and $\mathbf{8 4 . 0 \%}$ for a bodyweight. However, it is significantly lower in group II (extended norm) - $8.57 \%$ for height and $9.85 \%$ for body mass. The detected and registered main diseases and abnormalities in prophylactic examinations were: obesity, visual disturbances, spine curvature disorders, and asthma.
\end{abstract}

Keywords: anthropometric research, ability, dispensary observation, height, weight, physical development

Address for correspondence:

Daniel Monov

Training and Research Sector of Public Health Inspector,

Medical College,

Medical University of Varna

84 Tsar Osvoboditel Blvd

9000 Varna

e-mail:dmmonov@abv.bg 
Anthropometry, Physical Ability and Dispensary Observation of School-age Children - Contribution to ...

\section{INTRODUCTION}

The main morphological /anthropometric/ indicators are the basis for assessing the physical development of the body and the whole organism. External factors have an impact on growth and development, especially during puberty. The process of growth and development changes the hormonal background of the body. The impact of endogenous /genetic/ factors in school age also contributes to qualitative changes. This calls for appropriate measures and effective medical supervision to strengthen the body $(1,2,3,4)$.

\section{AIM}

We set ourselves the task to analyze anthropometric studies on students in organized groups in Varna - height, body weight, activity, and their dispensary observation by ICD for period of two years - 2012 - 2014.

\section{MATERIALS AND METHODS}

We have used reports, analyses, tests, data from prophylactic examinations and dispensary, anthropometric measurements (81 schools for 2013 and 99 for 2014 of a total 139 - average 65\%), laboratory tests of RHI Varna, examination of physical abilities and more. Methods: documentary, statistical, laboratory tests, physical abilities and more.

We have performed an analysis of the physical development of students and their morphological characteristics - height and body mass.

We have studied the physical development index height of 80771 school children in organized

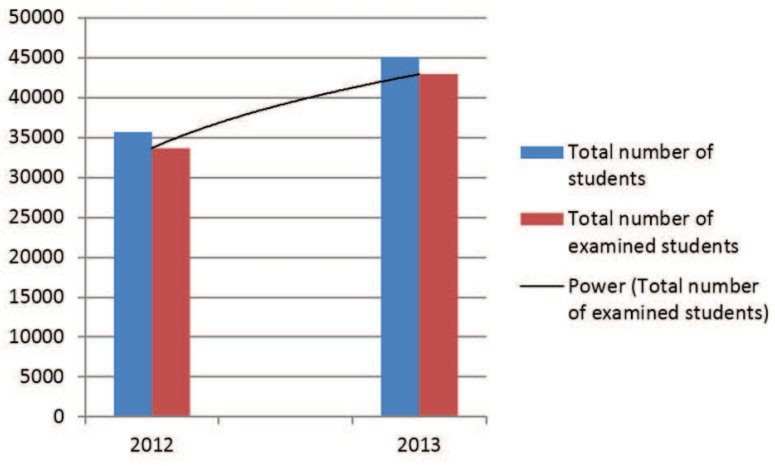

Fig. 1. Total number of students and the number of performed anthropometric studies in Varna for academic years 2012/13 and 2013/14 groups in Varna (for 2012/2013 - 33669 and for 2013/2014 - 42 918) based on individual assessment of anthropometric indicators in three groups: first group - norm, second group - extended norm, third - out of the norm. The anthropometry study for the two years covered - 94.8\%. The difference between the first and second year is insignificant - 94.4\% against $95.13 \%$. Fig. 1 shows the total number of the studied anthropometry data of students by year.

The index height in Fig. 1 shows the total student number and the number of performed anthropometric studies in Varna for 2012/13 and 2013/14.

The average percentage of students in the first group - norm is $87.0 \%$, for the first year it is $88.0 \%$ and $84.7 \%$ for the second $(\mathrm{P}<0.05)$. The assessment of height for the 2012/13 academic year is divided as follows: group I $-88.0 \%$, group II $-9.0 \%$, group III - 3\% (Fig. 2). During the 2013/14 academic year the covered by the survey students were 42918 (95.13\% of the total number of the subjects of study). The distribution in the three groups was as follows: group I /norm/ - 38 237- 84.7\%, group II / extended norm /$3595-7.9 \%$, group III /out of norm/ - $1086-2.41 \%$.

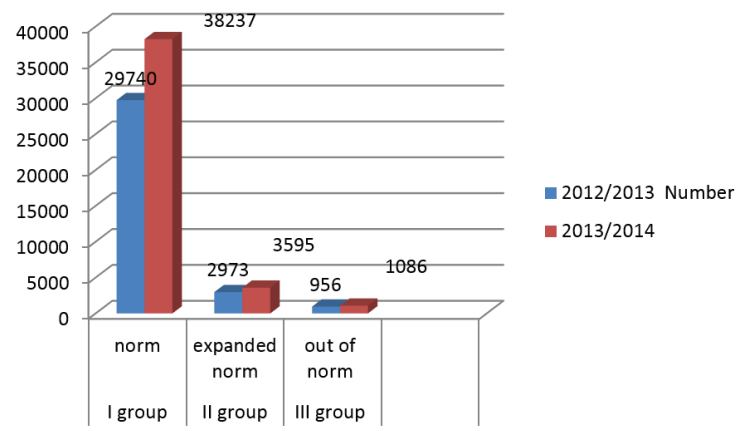

Fig. 2. Number of anthropometric studies on the height of students from Varna for the period 2012-2014

In 2013/14 the share of those with growth delay when it comes to height is greater in students from 7 to 14 years old - more than 3.7 times (362 students), compared to boys and girls aged 14 to 18 years -96 students.

The natural, physiological basis of a healthy body is weight. Its study is important for creating regimens and programs for adolescent students to meet the current requirements of the educational 
Daniel Monov, Genoveva Ragyovska, Yulia Vitlyanova

process (5). Fig. 3 shows a study on body mass and the percentages in each group. The average share (in $\%)$ of students within the norm in the first group is $84.0 \%$ (85.7\% for $2012 / 13$ and $82.3 \%$ for $2013 / 14$ ). For the second group extended norm the average is 9.85\% (10.3\% for $2012 / 13$ and $9.4 \%$ for $2013 / 14)$. Students with obesity are 2 times more than underweight students.

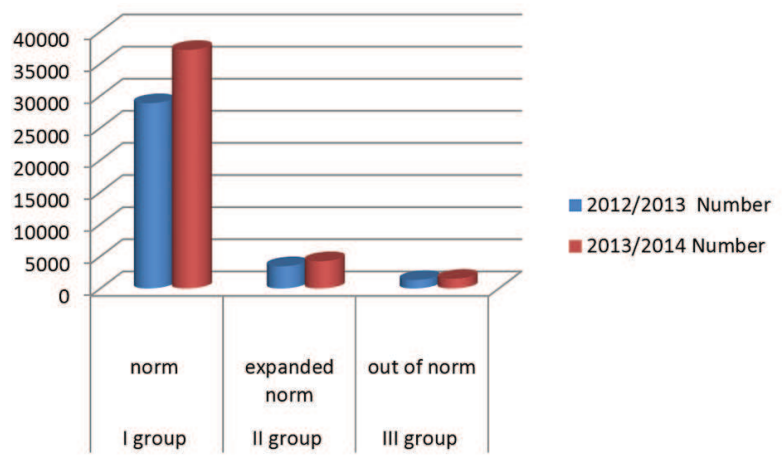

Fig. 3. Anthropometric studies - body mass of students in Varna for the period 2012 - 2014

Physical activity in school age, during puberty, plays an important role in the prevention of osteoporosis in adulthood, helping to increase bone mass. It contributes to the improvement of mental functioning, as well as overall health and self-esteem $(6,7)$. Figure 4 shows the number of students who passed and did not pass the tests of physical ability. The assessment of those who have covered the norms is: $94.0 \%$ for the first year and $93.8 \%$ for the second year, while those who did not cover the norms are few $6.0 \%$ and $6.2 \%$, accordingly.

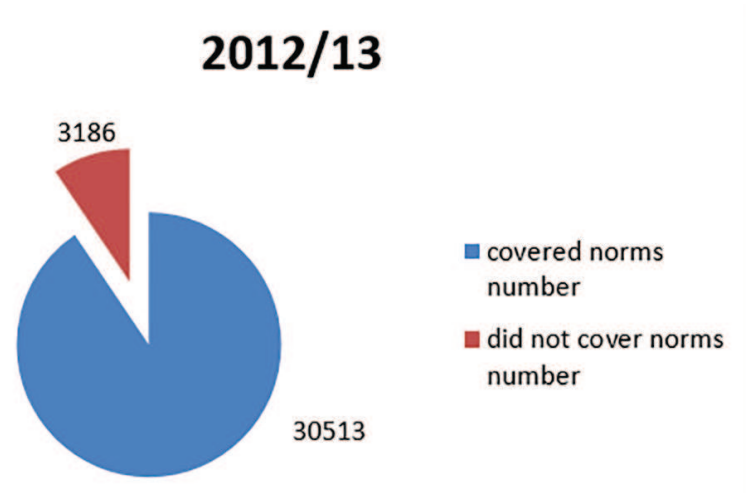

The study also includes students exempted from physical education and those of remedial gymnastics.

Indirect assessment of the physical development of students is done through medically controlled growth and development via periodic preventive examinations based on the age. (Ordinance No. 39/2004, State Gazette, issue 106, annex 1) (1,2).

The most common impairments in the physical development of students were as follows: obesity 2011 - 1236 students, 2012 - 1288 students, 2013 1632 students; spinal curvature for 2011 - 886 students, 2013 - 556 students.

ICD dispensary observation of students for the academic year 2013/14 included a total number of 1936. The leading disease was asthma (J 45.0-1) 453 students. Students aged 7 to 14 years were 378 and 5 times more than those in the age group 14-18 years -75 . In second place among students is a decrease of vision in both eyes - (H 54.2) - 430 cases. And for this condition, the number of students from 7 to 14 years of age is 368 and is 6 times higher than that at those aged 14-18. Cases of epilepsy are at third place (G 40.0-8) - 123 students. The total number of girls (68) is higher than that of boys (55). Fourth place is for allergic rhinitis caused by pollens (J 30.1) - 89 students. The number by sex and age is the same for both groups 1084 .

Registered diseases and abnormalities in the main prophylactic examination of students at a distribution of $95 \%$ over the past three years shows that the number of students with obesity increases - 1362 (for 2011- 1236, for 2012 - 1288 and for 2013 - 1362 cases). The incidence of obesity in first grade is $9 \%$,

Fig. 4. Physical abilities of students in Varna for the period 2012-2014 
Anthropometry, Physical Ability and Dispensary Observation of School-age Children - Contribution to ...

while for seventh graders it is $12 \%$. The lowest rate is the indicator for tenth grade - $6 \%$. Obesity in the first and seventh grade has increased in comparison to the previous year, while in tenth grade no change was detected. In second place are the cases of visual disturbances - 670 cases. The largest share of these diseases is in seventh grade - $85(12 \%)$ and the lowest in first grade - 57 (8\%). The number of students who have spinal curvature continues to decrease - from 886 in 2011 to 556 in 2013. This disease continues to be in third place for a second year. In fourth place are registered cases of asthma - 653 newly diagnosed. Of these, the largest number of students with asthma are in first grade - 63 and the lowest - in tenth grade - 39 cases. With the increase of age, the frequency and the proportion of asthma is reduced, which is characteristic for the development of the disease.

\section{DISCUSION}

Parents and educators should be informed regularly about the benefit of medical check-ups and the need for eyesight to be examined once a year by a specialist, as well as how to maintain correct posture during lessons.

\section{CONCLUSIONS}

1. The share of anthropometric measurement of height and weight within the norm is highest in schoolchildren in group I (norm) - 87.0\% for a height and $84.0 \%$ for a bodyweight. It is significantly lower in group II (extended norm) - $8.57 \%$ for height and $9.85 \%$ for a body mass and for group III (outside the norm) - 2.66\% for height and $3.7 \%$ of body weight (at the expense of values above the norm for height /higher height/ and above the norm for weight /high body mass/).

2. The results show that those who have covered the norms are: $94.0 \%$ for the first year and 93.8\% for the second year, while the share of those who have not covered the norms is small $6.0 \%$ and $6.2 \%$, accordingly.

3. Detected and registered main diseases and abnormalities in prophylactic examinations: obesity, visual disturbances, spine curvatures, asthma.

\section{REFERENCES}

1. An ordinance No. 3 of the Ministry of Health for Practices in kindergartens and schools - SG 38/2000; amend. and supplemented SG 83/2000.

2. An ordinance No. 39 of 2004 for prophylactic examinations and dispensary, SG 106/2004.

3. Ordinance for transformation and Rules for the activity of RIPCPH / SG 16 of February 18, 2005

4. Ordinance No 1 of January 6, 2011, issue 5 of SG, 14.01.2011 / Converts existing regional health centers and Regional Inspectorates for Protection and Control of Public Health in regional health inspections

5. Popov B. Hygiene, nutrition and epidemiology. First edition. Sofia; 2007: 127-138, 290.

6. Valkova M. Aesthetic attitude to seventeen. Electronic Publishing Varna: LiterNet; 2006.

7. Simeonova I, Velikova A. Age as a determinant of differences in the level of physical activity of people from MU-Pleven. Reports Volume 1. Anniversary scientific conference 30 sept. - 2 oct. 2010. Publishing center MU Pleven; 2010: 80-84. 